\title{
SHAPING THE PARAMETERS OF CYLINDRICAL BELT SURFACE IN THE JOINT AREA
}

\author{
Krzysztof WAŁĘSA, "Ireneusz MALUJDA, ${ }^{\star}$ Dominik WILCZYŃSKI ${ }^{\star}$
}

*Institute of Machine Design, Poznań University of Technology, ul. Piotrowo 3, 61-138 Poznań, Poland

krzysztof.walesa@put.poznan.pl, ireneusz.malujda@put.poznan.pl, dominik.wilczynski@put.poznan.pl

received 24 October 2019, revised 13 January 2020, accepted 15 January 2020

\begin{abstract}
Most of the industrial machines use round-shaped drive belts for power transfer. They are often a few millimetres in diameter, and made of thermoplastic elastomer, especially polyurethane. Their production process requires the bonding step, which is often performed by butt welding, using the hot plate method. The authors have undertaken to design an automatic welding machine for this purpose. Consequently, it is required to carry out a process analysis of hot plate welding, which entails describing the dependency between technological parameters (temperature, pressure force, time) and the quality of the joint, especially the outer surface of the belt around the weld. To analyse this process in a proper way, it is necessary to describe the physical phenomena that occur in the material, during particular operations of the hot plate welding process. One of the most troublesome phenomena occurring during the welding process is removing of the flash. These round rings, placed around the weld, which remains after the joining process, are unacceptable in the finished component. The authors took an effort to design the necessary equipment for removing of the flash after welding, using some simple parts that cut off excessive material. The paper shows the three possible solutions for flash removal. They were verified experimentally, and afterwards, the best solution was chosen. Additionally, a number of analytical calculations were carried out in order to determine the maximum force value required for this operation. Results of the analytical calculations were compared with experimental results.
\end{abstract}

Key words: Hot plate welding, flash, flash removing, surface processing, cutting, round drive belts

\section{INTRODUCTION}

Industrial grade belts, both used in drives and conveyors, are commonly utilized in machine building for transferring torque between the connected workstations or for transporting products on manufacturing lines. Both full cross-section and perforated conveyor belts are utilized in transportation; the latter are utilized in vacuum transportation of light objects (Wojtkowiak et al., 2018; Wojtkowiak and Talaśka, 2019). On the other hand, the most commonly used types of drive belts are flat, toothed and shaped belts. Toothed belts are used both in simple transmissions as well as non-classical solutions, for example, with variable ratios (Domek and Dudziak, 2011; Domek et al., 2016; Krawiec et al., 2018; Krawiec et al., 2019). Shaped belts, in particular V-shaped and round belts are commonly employed in drives, that is, special robotic arm joint mechanism, with two twisted small diameter belts (Inoue et al., 2016), they can be made of rubber (Kukla et al., 2015 and 2019) or polyester or polyurethane based elastomers (Behabelt, 2015). Their common application in industrial machines calls for an efficient manufacturing process, which usually takes place in two stages (Sikora, 1993). First of all, a long belt is manufactured and cut down to the required size. Finally, the ends are joined permanently to form a continuous loop (Wałęsa, 2018).

Due to the peculiar characteristics of the thermoplastic elastomers used in the manufacturing of such belts, it is possible to join them by hot welding. A specific approach to this process is butt-welding utilizing the hot plate method; it is popular due to its simplicity and efficiency (Grewell and Benatar, 2007; Yousepour et al., 2004). This method is commonly employed in the automotive industry and civil engineering, for example, in the process of joining: tanks for utility fluids, lamp enclosures, engine instrumentation (Pietrzak et al., 2019; Grewell and Benatar, 2007) and pipes (Rzasinski, 2017; Troughton, 1997; Cocard et al., 2009). Furthermore, studies were carried out on the hot welding of inflexible polymer materials, for example, acrylonitrile butadiene styrene copolymer (ABS) (Mokhtarzadeh and Benatar, 2012), polycarbon (PC) (Krishnan and Benatar, 2004), as well as polypropylene (PP) (Nieh and Lee, 1992). However, it needs to be pointed out that all of them apply primarily to plastics.

The authors started design works on a device for automated butt welding of drive belts utilizing the hot plate technique (Wałęsa et al., 2018), which is to improve the efficiency of the manufacturing process of continuous belts. For the purpose of verification of the design assumptions, the process was to be analysed together with further study of the influence of heating parameters on weld quality (Wałęsa et al., 2019a and 2019b). It was assumed that the drive belt made of TPU C85A polyurethane, commonly marketed by drive belt manufacturers (BASF, 2010) will be hot welded. A review of the available subject literature has concluded that information on this method of connecting thermoplastic elastomers is difficult to obtain.

The butt welding process utilizing the hot plate method can be divided into 5 stages (Wałęsa et al., 2019; Klimpel, 1999 and 2000; Potente et al.; 2002, Jasiulek, 2006). One of the most important activities is the plasticization of the belt end, which enables the chemical reaction and physical interaction between the macromolecules in the joining process (Amanat et al., 2010; Amancio-Filho and dos Santos, 2009; Madej and Ozimina, 2010; Puszka, 2006; Żuchowska, 2000). The welding temperature choice is a very important issue. Exceeding some values causes 
destruction of the material volume in a few stages (Wanqing et al., 2017). On the other hand, in case of some polymers, joint strength increases with welding temperature (Evers et al., 2017). When the heating and cooling process is considered, also it should be noted some division in the three zones with different impact of temperature. This phenomenon can be observed in all of the semicrystalline thermoplastic polymers, so in butt welding of round belts, it has some impact to the process (Casalino and Ghorbel, 2008). The plasticization of the belt material due to temperature and compression forces activities, results in a flash forming in the final stage of the process (Fig. 1).

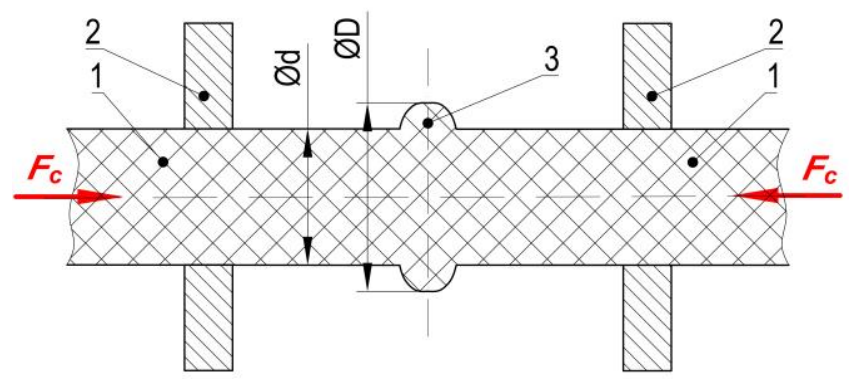

Fig. 1. Forming of the flash in the final stage of the drive belt hot welding: 1 - belt end, 2 - grips, 3 - flash; $F_{c}$ - pressure force during the final stage of the hot welding, $d$ - belt diameter, $D$ - external flash diameter

The flash constitutes excessive material in the form of a ring with diameter $D$ around the weld, caused by the pressing of the plasticized belt end towards the hot plate with force $F_{c}$.

The removal of flash is a significant problem in the aspect of automating the manufacturing process of these belts, as the belt forms a continuous circuit as a result of this welding. Therefore, this operation is often performed manually, using simple tools such as shears. Striving to optimize the entire manufacturing process of the belts, a method to remove the post-weld flash was devised, which entails automatic shearing with use of profiled cutting sleeves; furthermore, the necessary instrumentation was also designed. In order to select the correct components of the drive system, it is necessary to estimate the process forces during this technical operation.

Subject literature provides formulas for calculating the necessary force for cutting various materials using dies for, for example, sheet metal, leather and plastics (Groover, 2017; Marciniak, 1959) as well as composite belts (Wilczyński et al., 2019; Wojtkowiak et al., 2018). However, these approaches fail to account for the peculiar construction features of dies used when the belt is continuous. For this reason, the developed construction solution must be analysed and subject to empirical examination in order to verify its correct operation.

Study of the technological process of hot welding and drive belt processing after the weld was made are problematic as the joined material exhibits non-classical thermomechanical characteristics (Broniewicz et al., 1970). This is shared by other materials, for example, crystallized carbon dioxide (Górecki et al. 2019), fragmented natural materials (Talaśka, 2018), organic fibres (Talaśka and Ferreira, 2017) or glues (Fierek et al., 2019), and predicting their behaviour under mechanical and thermal load conditions is problematic. One needs to consider that the influence of temperature on the characteristics of such polymers is significant (Ciszewski and Radomski, 1989; Sikora, 1993). With this fact in mind, experimental study to determine the behaviour of belt material during the removal of the flash is called for.

In order to determine the force value necessary to carry out this operation, analytic calculations and experimental studies were performed on the process of cutting off the flash. As a consequence, the characteristics of the process of flash removal utilizing this method were determined, with particular emphasis on the maximum force value utilized in the shearing process. Cutting tests were carried out for three cases of designed instrumentation assemblies, together with analytical calculations, which lead to obtaining maximum cutting force, for one of them.

\section{STUDY METHODOLOGY}

The study utilized conical blades of the author's own design with different apex angle values: $10^{\circ}, 20^{\circ}, 30^{\circ}$ and $40^{\circ}$, manufactured with steel hardened to $58 \mathrm{HRC}$ (Fig. 2).
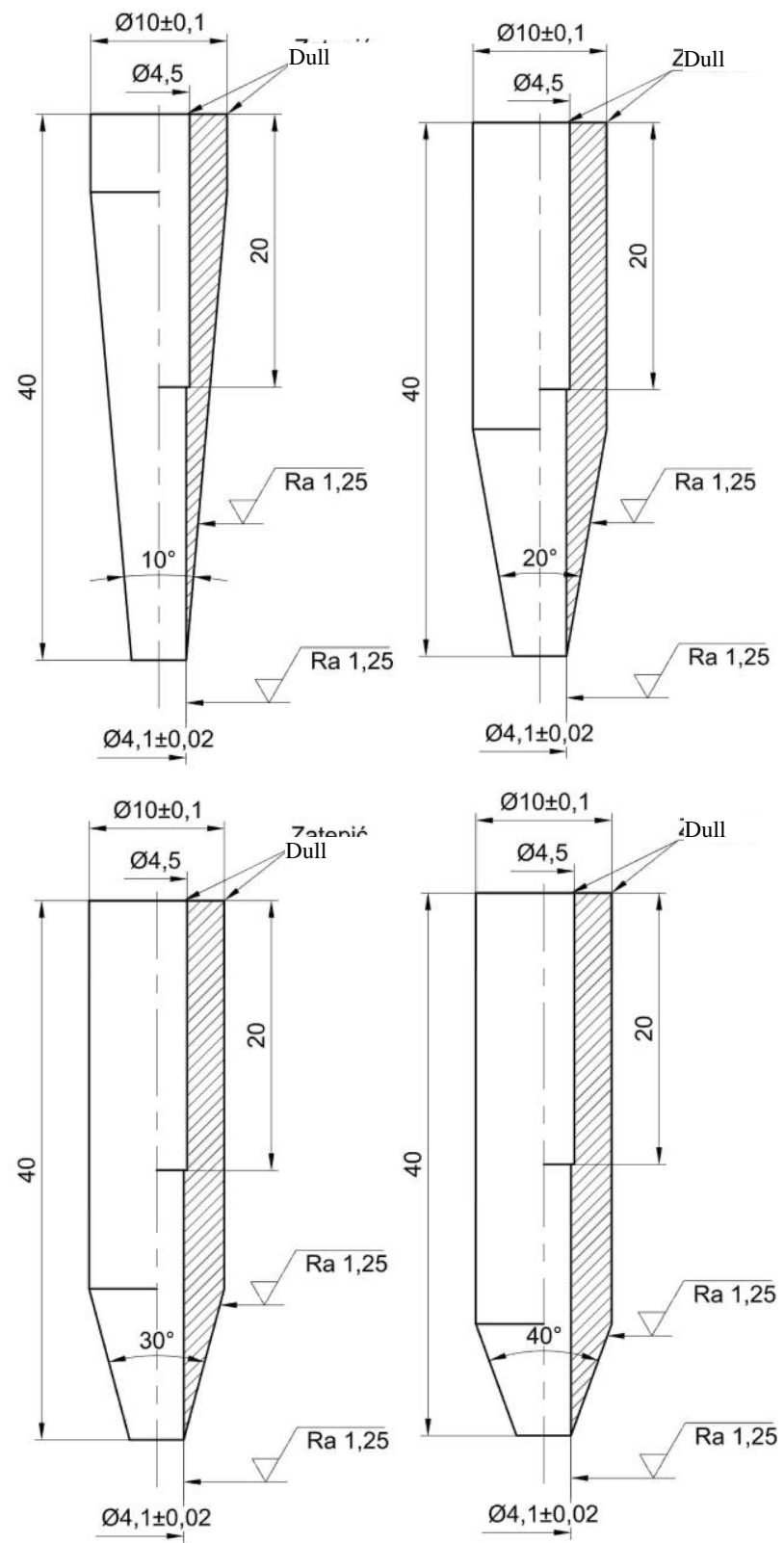

Fig. 2. Executive drawings for the blades used in the study with apex angle values: $10^{\circ}, 20^{\circ}, 30^{\circ}$ and $40^{\circ}$ 
For the assumed fixed blade geometry, three methods of flash removal were assumed, which are possible in the proposed construction solution:

- two-sided cutting of the flash with cutting force $F_{T}$ vectors in opposite directions, distributed evenly at the belt circumference, acting in contact with the round external surface of the belt. This method is achieved by compressing the flash between two identical blades (Fig. 3), whereas both blades are movable in relation to one another,
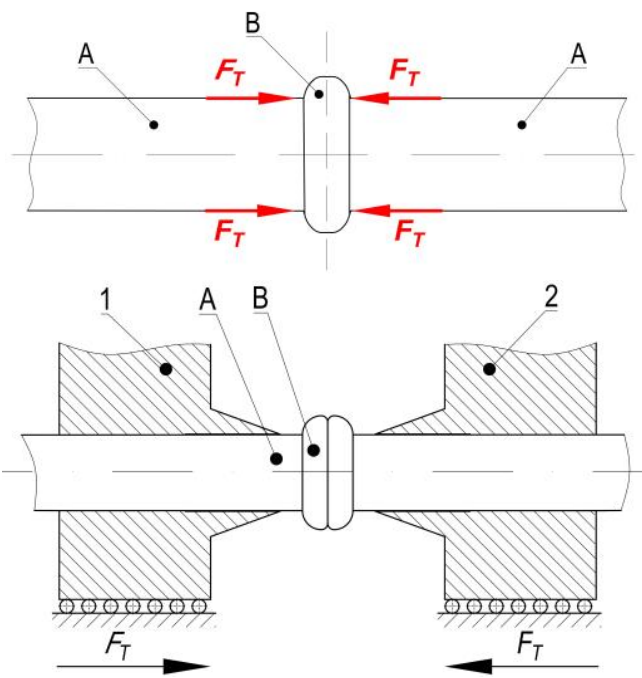

Fig. 3. Two-sided cutting of the flash with cutting forces in opposite directions, together with an implementation example: $A$ - belt ends, B - flash, 1 and 2 - cutting sleeves; $F_{T}$ - forces cutting off the flash

- one-sided cutting of the flash using $F_{T}$ cutting forces distributed evenly along the circumference of the belt, acting in contact to the round external surface of the belt, with additional force $F_{c}$ acting along the belt axis with opposite sense (Fig. 4). This method is carried out by drawing the belt with flash towards the blade,
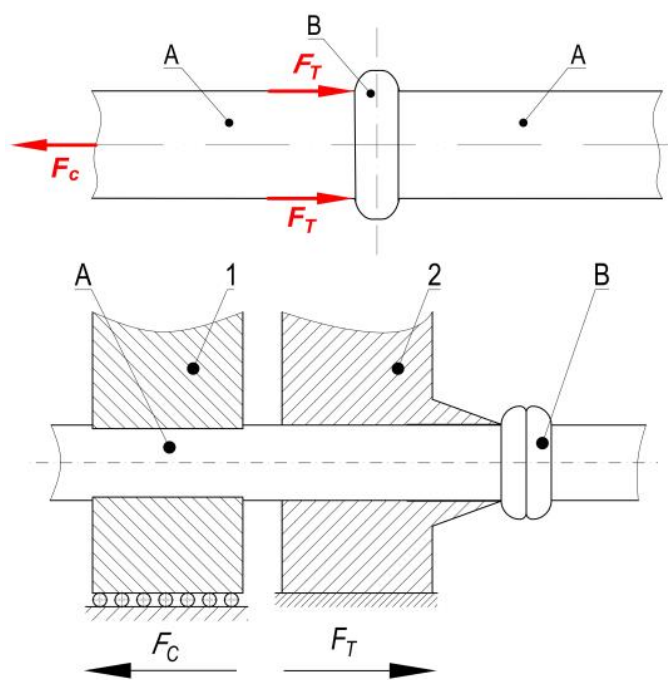

Fig. 4. One-sided cutting of the flash with force drawing the belt in the opposite direction: A - belt end, B - flash; $F_{T}$ - forces cutting off the flash, $F_{c}-$ force drawing the belt through the sleeve, 1 - drawing sleeve, 2 - cutting sleeve
- one-sided flash cutting using forces $F_{T}$, distributed evenly at the belts circumference, acting in contact to the round external surface of the belt, with additional plate supporting the flash (Fig. 5). Its use causes a reaction force $F_{p}$, which prevents the movement of the flash and increases the effectiveness of the removal process. The implementation entails pressing the flash by the blade towards the support plate made of PA6 aluminium, with bore diameter allowing to freely move out the belt.
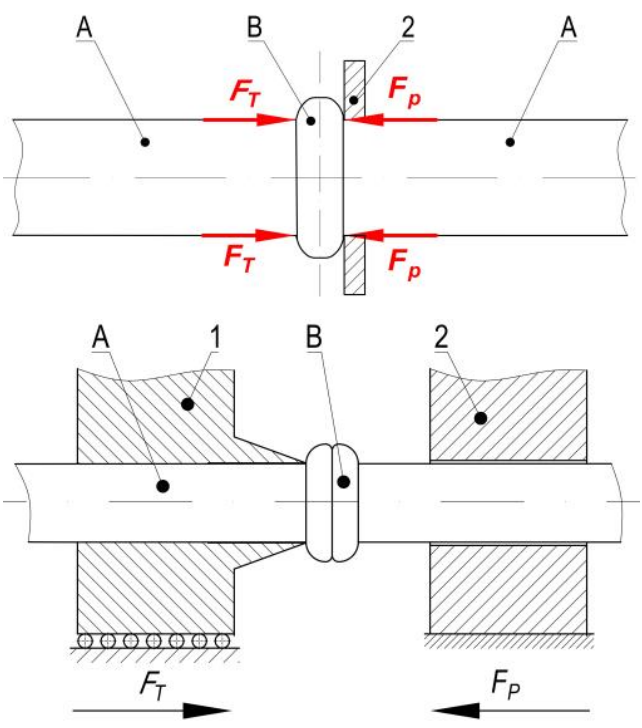

Fig. 5. One-sided cutting of the flash with support: A - belt end, B - flash, 1 - cutting sleeve, 2 - support plate; $F_{T}$ - forces cutting off the flash, $F_{p}-$ reaction force of the support plate

The tests were carried out for 4 different rake angles, for welded belt sections with average diameter $d_{c}=4,11 \mathrm{~mm}$. Cutting tests were performed on sixteen samples for each blade angle. The testing utilized the MTS Insight $50 \mathrm{kN}$ durometer with standard grips, flat supporting board with openings together with a supporting plate (Fig. 6). The samples were hot welded belt sections of random length (Fig. 7).

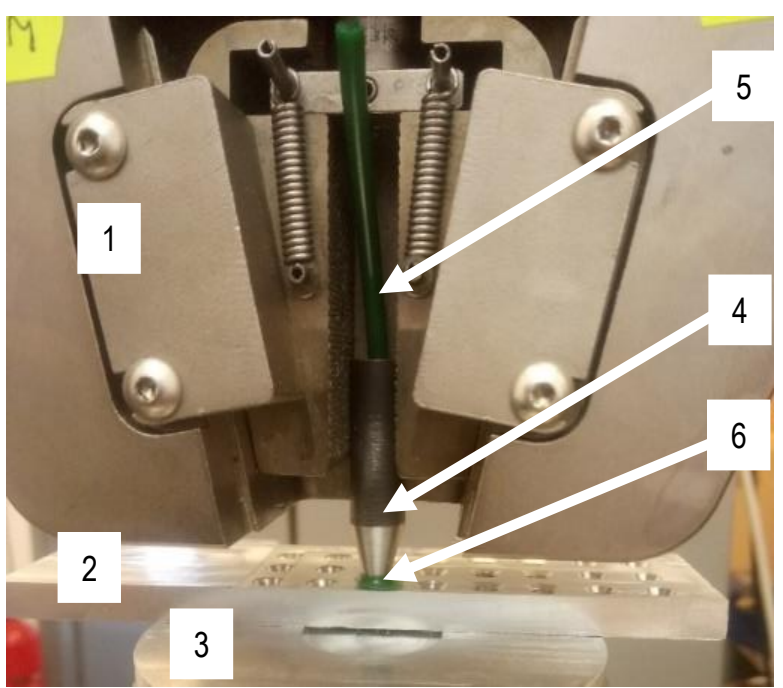

Fig. 6. The testing station during the examination of the flash removal process utilizing the third method: 1 - durometer grip, 2 - supporting plate with holes, 3 - supporting plate, 4 - cutting sleeve, 5 - belt, 6 - flash 


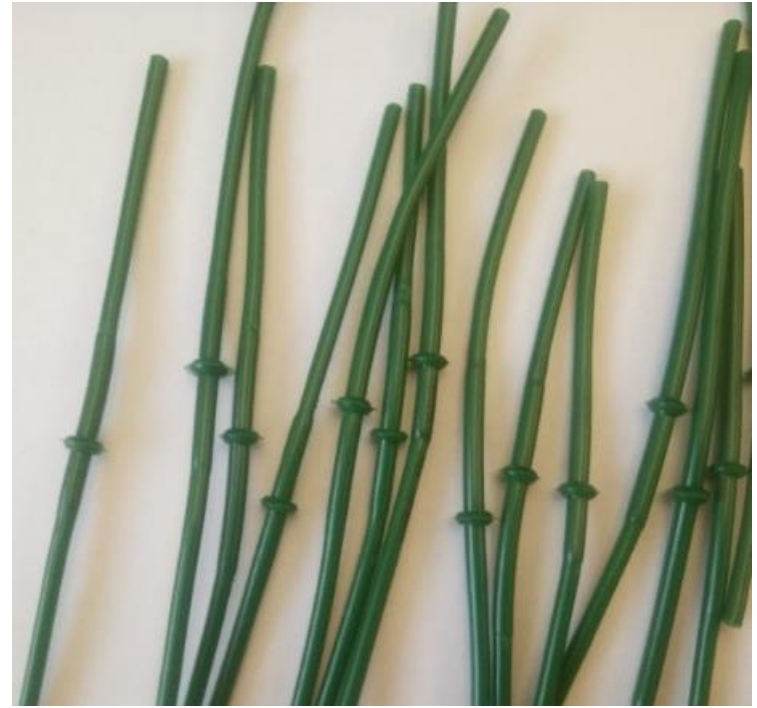

Fig. 7. Belt samples with flashes, prepared for the study

Additionally, for the third method of removal, analytical calculations were carried out to determine the force value necessary to remove the flash, utilizing the balance of forces between the belt and the blade. Based on the dimensions of the blade and the belt (Fig. 8) as well as the distribution of forces between them (Fig. 9), it is possible to derive a general formula to calculate the force value required to remove the flash using this technique.

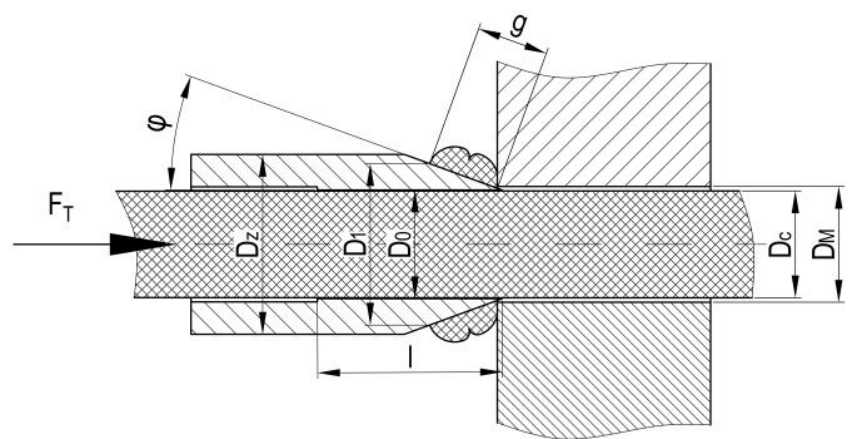

Fig. 8. Dimensions assumed for the analytical calculations: $\varphi$ - blade inclination angle, $D_{z}$ - internal diameter of the cutting sleeve, $D_{0}$ - bore diameter of the cutting sleeve, $D_{c}$ - external belt diameter, $D_{M}$ - support bore diameter, $g$ - flash thickness, $F_{T}$ - force necessary to remove the flash, $I$ - length of contact area between the belt and the blade

The process force required to remove the flash $F_{T}$ can be expressed with the formula below:

$F_{T}=F_{T r}+F_{T 1}+F_{T 2}$,

where: $F_{T}$ - flash removal process force, $F_{T r}$ - component of cutting force from flash stretching on the conical surface of the blade, $F_{T 1}$ - cutting force component from flash friction on the conical surface of the blade, $F_{T 2}$ - force component from belt friction inside the blade bore.

Considering $F_{T r}$, according to the force distribution (Fig. 9), may be expressed as follows:

$F_{T r}=F_{r} \cdot \sin \varphi=p_{1} \cdot A_{s}$, inclination angle, $p_{1}-$ flash bearing pressure on the blade surface, $A_{s}$ - conical surface constituting the blade side on which the deformed flash is present. It should be therefore noticed that the flash surface in contact with the conical blade side can be calculated from the following formula:

$$
A_{s}=\pi \cdot g \cdot\left(D_{0}+g \cdot \sin \varphi\right) \text {. }
$$

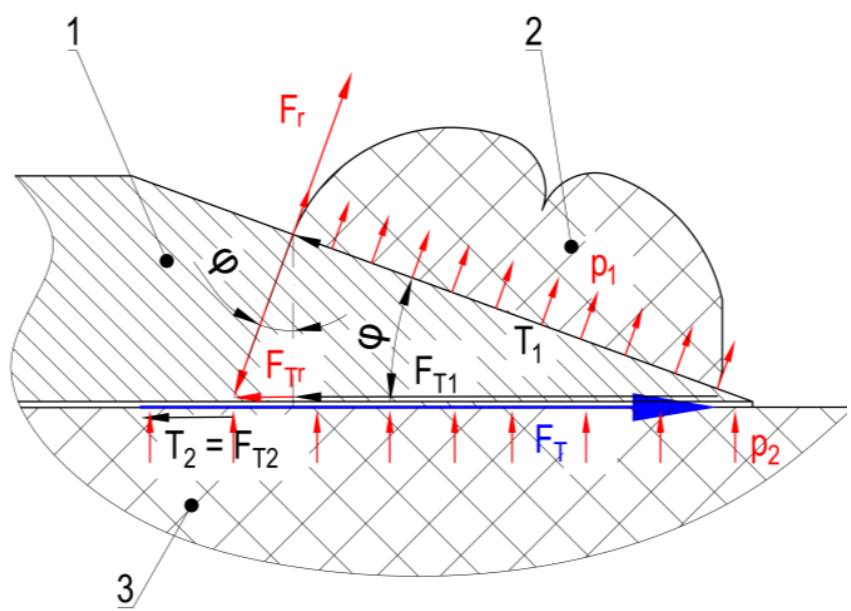

Fig. 9. The dependence between force vectors during flash removal: $1-$ blade, 2 - flash, 3 - belt; $F_{T}$ - flash removal process force, $F_{T r}-$ cutting force component from the stretching of the flash on the conical surface of the blade, $F_{T 1}$ - force component from flash friction on the blade conical surface, $F_{T 2}-$ force component from belt friction inside the blade bore, $F_{r}$ - singular force stretching the flash, $\varphi$ - blade side angle of inclination, $p_{1}$ - flash bearing pressure on the blade surface, $T_{1}$ - total frictional force on the blade surface, between the flash and the conical blade surface, $T_{2}-$ total frictional force between the belt surface and blade bore

Contact stress $p_{1}$, can be calculated from Hooke's law, assuming average deformation on the conical surface for calculation (Osiński, 2007):

$p_{1}=\varepsilon_{A V G} \cdot E_{p}$,

where: $\varepsilon_{A V G}$ - mean flash deformation of the conical surface which is identified in the radial direction, $E_{p}$ - longitudinal flexural modulus of the belt material. Mean deformation can be determined from the following formula:

$\varepsilon_{A V G}=\frac{D_{A V G}-D_{0}}{D_{0}}$

where $D_{A V G}$ mean diameter of the flash on the blade, and it is determined from the formula:

$D_{A V G}=\frac{D_{1}+D_{0}}{2}$.

The external diameter of the flash on the blade can be calculated as below:

$D_{1}=D_{0}+2 \cdot g \cdot \sin \varphi$.

Considering the formulas 2-7, the component of cutting force from flash stretching on the conical surface of the blade $F_{T r}$, can be determined from the formula as below:

$F_{T r}=\frac{g^{2} \cdot \sin ^{2} \varphi \cdot E_{p} \cdot \pi}{D_{0}} \cdot\left(D_{0}+g \cdot \sin \varphi\right)$.

where: $F_{r}$ - singular force stretching the flash, $\varphi$ - blade side 
Tab. 1. Major parameters assumed for calculating the process force for removal of flash after butt welding of drive belts

\begin{tabular}{|c|c|c|c|c|c|c|}
\hline 1 & Designation: & \multicolumn{2}{|c|}{ Value: } & Source: \\
\hline Blade side angle of inclination & $\varphi\left[^{\circ}\right]$ & 5 & 10 & 15 & 20 & Assumed - manufactured blades \\
\hline Blade bore diameter & $D_{0}[\mathrm{~mm}]$ & 4.1 & 4.1 & 4.08 & 4.09 & Measured \\
\hline Average belt diameter during examination & $D_{c}[\mathrm{~mm}]$ & 4.11 & 4.11 & 4.11 & 4.11 & Measured \\
\hline $\begin{array}{c}\text { Length of the cylindrical section of the } \\
\text { blade }\end{array}$ & $I[\mathrm{~mm}]$ & 20 & 20 & 20 & 20 & Assumed \\
\hline $\begin{array}{c}\text { Poisson's coefficient of the belt } \\
\text { Young's modulus of the belt }\end{array}$ & $\vartheta_{p}[\mathrm{MPa}]$ & 50 & 50 & 50 & 50 & Assumed \\
\hline Poisson's coefficient of the sleeve & $\vartheta_{t}$ & 0.33 & 0.33 & 0.33 & 0.33 & Assęsa et al., 2019) \\
\hline Young's modulus of the sleeve & $E_{t}[\mathrm{MPa}]$ & 210000 & 210000 & 210000 & 210000 & Assumed \\
\hline Flash thickness & $g[\mathrm{~mm}]$ & 1.60 & 1.73 & 1.81 & 1.96 & Measured \\
\hline
\end{tabular}

The component $F_{T 1}$ of the $F_{T}$ is the process force from friction of the flash on the conical surface of the blade can be derived from the general dependence:

$F_{T 1}=T_{1} \cdot \cos \varphi$,

where $T_{1}$ - is the total frictional force on the blade surface, between the blade surface, between the flash and the conical surface of the blade. The value can be calculated from the below formula:

$T_{1}=\frac{F_{r}}{\operatorname{tg} \varphi}$

Force stretching the flash $F_{r}$, considering the formulas 2-7 is expressed as follows:

$F_{r}=\frac{F_{T r}}{\sin \varphi}=\frac{g^{2} \cdot \sin \varphi \cdot E_{p} \cdot \pi}{D_{0}} \cdot\left(D_{0}+g \cdot \sin \varphi\right)$.

Considering the formulas 9,10 and 11 , the force value $F_{T 1}$ is ultimately derived from the formula:

$F_{T 1}=\frac{g^{2} \cdot \cos ^{2} \varphi \cdot E_{p} \cdot \pi}{D_{0}} \cdot\left(D_{0}+g \cdot \sin \varphi\right)$.

The component $F_{T 2}$ of the cutting force $F_{T}$, from the friction of the belt on the cylindrical surface of the blade bore can be derived from the formula:

$F_{T 2}=p_{2} \cdot \pi \cdot D_{0} \cdot l \cdot \mu$,

whereas: $\mu$-coefficient of friction between the belt and the cutting sleeve, $p_{2}-$ belt bearing pressure in the blade bore, which can be determined from the formula (Osiński, 2007):

$p_{2}=c \cdot w$,

where, $w$ - effective relative interference of belt and sleeve composition, which can be calculated with the formula as below:

$w=\frac{D_{c}-D_{0}}{D_{0}}$,

as well as the strain coefficient of the coupled pair belt-sleeve $c$, is calculated from the formula:

$c=\frac{1}{\frac{\delta_{t}+\vartheta_{t}}{E_{t}}+\frac{\delta_{p}+\vartheta_{p}}{E_{p}}}$

where, $\delta_{t}$ - is the characteristic coefficient of the coupling for the sleeve, whereas $\delta_{p}$ - is the characteristic coefficient for the belt. These coefficient are calculated using the formulas:
$\delta_{t}=\frac{1+\frac{D_{0}^{2}}{D_{Z}^{2}}}{1-\frac{D_{0}^{2}}{D_{Z}^{2}}}$,

$\delta_{p}=\frac{1+\frac{D_{W}^{2}}{D_{C}^{2}}}{1-\frac{D_{W}^{2}}{D_{C}^{2}}}$

The calculations following the presented methodology were carried out for all rake angles. Major variable values used in the calculations are provided in Table 1.

\section{RESULT ANALYSIS}

The study with the first proposed method of removing the flash, that is, using two blades and compressing the flash between them has failed. During the first test, the blades were damaged by the sharp, brittle edges of the blades colliding in the final stage of the operation. It was therefore decided to discontinue further examination using this method as under industrial conditions, it is unacceptable to damage the working components after each processed belt.

The study of the second proposed method, that is, drawing the belt with the flash between the blades were also unsatisfactory. The flash was not removed completely. This is caused by the peculiar characteristics of the belt material, it is very flexible and subject to significant flexible deformation. The belt would become significantly elongated before the blade, reducing its diameter. The flash was similarly deformed, which caused it to squeeze through the bore in the cutting sleeve without being removed. Consequently, further examination using this method was discontinued.

The study of the third method, that is, pressing the flash with the blade to a flat support with an opening proved to be successful. The flash was removed in its entirety in every attempt. The results of empirical study as well as analytical calculations are juxtaposed in Table 2 and Fig. 10. For the considered processing method, a relatively good approximation of actual examination results were obtained with the analytical model. The difference in the results, no more than approx. $8 \%$ was caused by the likely occurrence of flexing reactions during the removal process. Furthermore, a good repeatability of empirical study results was achieved. 
Tab. 2. Results of analytical calculations and empirical data of one-sided cutting of flash with support plate

\begin{tabular}{|c|c|c|c|c|}
\hline \multicolumn{5}{|c|}{ Analytical calculations } \\
\hline Blade inclination $2 \varphi\left[^{\circ}\right]$ & 10 & 20 & 30 & 40 \\
\hline Force constituent from stretching of the flash $F_{T r}[N]$ & 3.80 & 18.23 & 46.01 & 98.19 \\
\hline Force constituent from friction between the flash and blade $F_{T 1}[\mathrm{~N}]$ & 496.19 & 586.40 & 640.87 & 741.20 \\
\hline Force constituent from friction between the belt and sleeve bore $F_{T 2}[\mathrm{~N}]$ & 12.56 & 12.56 & 37.69 & 25.12 \\
\hline Total calculated flash cutting force $F_{T}[\mathrm{~N}]$ & 512.55 & 617.19 & 724.57 & 864.50 \\
\hline \multicolumn{5}{|c|}{ Empirical data } \\
\hline Average flash cutting force $F_{T}[\mathrm{~N}]$ & 554.85 & 643.10 & 740.45 & 897.74 \\
\hline Standard deviation of population $\sigma[\mathrm{N}]$ & 70.81 & 51.43 & 67.65 & 128.84 \\
\hline Percentage difference between empirical and analytical data [\%] & 8.25 & 4.20 & 2.19 & 3.84 \\
\hline
\end{tabular}
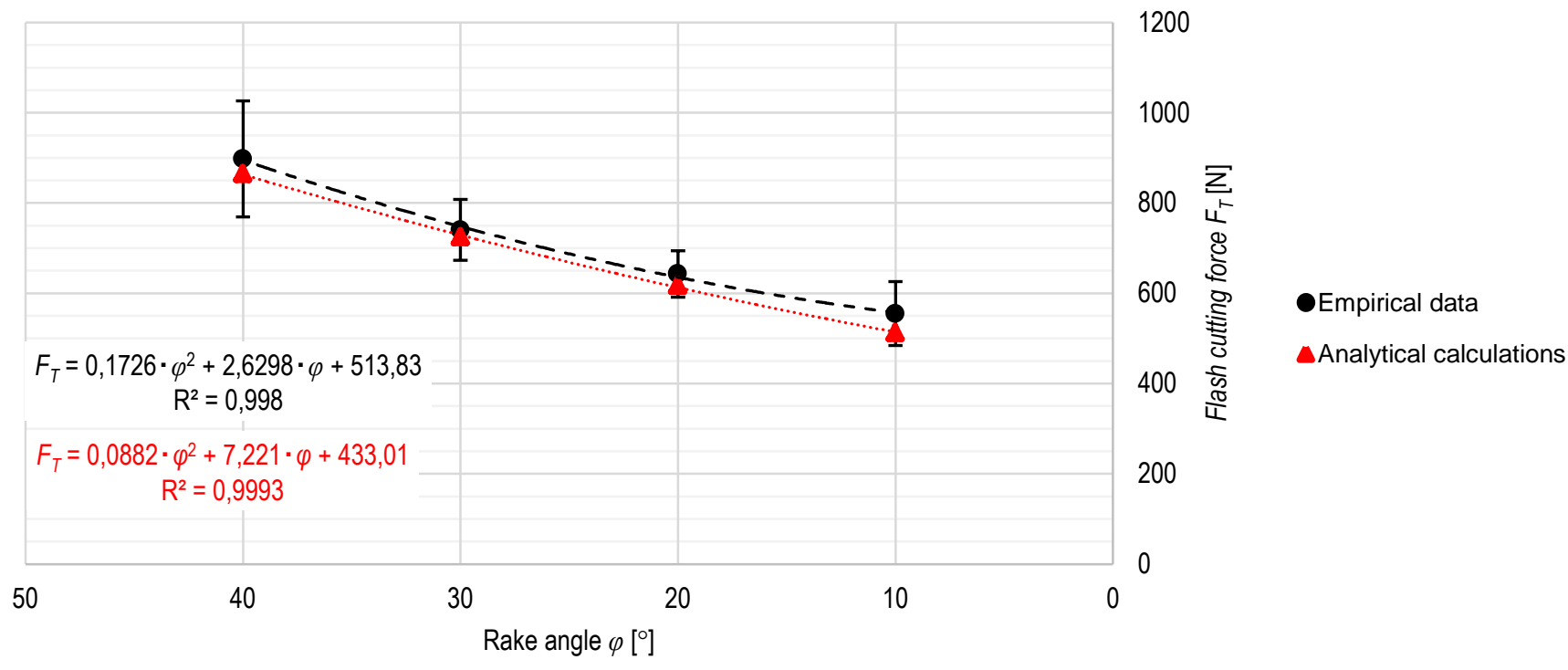

Rake angle $\varphi\left[^{\circ}\right]$

Fig. 10. Results of empirical examination and analytical calculations of force required for removal of the flash depending on rake angle

\section{CONCLUSIONS}

The removal of flash after hot plate butt welding is a deceptively simple technical operation with easy to implement kinematics in an automated device. However, the peculiar characteristics of the processed material (primarily, the high flexibility of the belt) mean that not every processing method can be successfully employed in this case. As indicated by the performed examinations, the removal of the flash utilizing the double blade method is possible, but not suitable for application under industrial conditions. The method of one-sided cutting of the flash by drawing the belt through the conical blade was also unsuccessful due to high flexibility of the belt.

Therefore, the best approach to carry out this process is onesided cutting action utilizing a supporting plate. Analysing both the calculated and empirical data, one can observe a significant increase of the cutting force on the flash with the increase of the blade rake angle. As indicated in the analysis of force distribution during flash removal, it is caused by a material increase of the stretching force of the flash on the surface of the conical blade, which subsequently causes a material increase in the frictional force on the conical section of the blade together with the increase in rake angle.

\section{REFERENCES}

1. Amanat N., James N. L., McKenzie D.R. (2010), Welding methods for joining thermoplastic polymers for the hermetic enclosure of medical devices, Medical engineering \& Physics, 32, 690-699.

2. Amancio-Filho S.T., dos Santos J.F. (2009), Joining of Polymers and Polymer-Metal Hybrid Structures: Recent Developments and Trends, Polymer Engineering and Science, 49(8), 1461-1476.

3. BASF (2010), Thermoplastic Polyurethane Elastomers, Elastollan ${ }^{\circledR}$ Material Properties, BASF.

4. Behabelt (2015), Product Catalogue 2015/2016, Behabelt, Glottertal.

5. Broniewicz T., Iwasiewicz A., Kapko J., Płaczek W. (1970) Methods of researches and examination of plastics properties (in Polish), WNT, Warszawa.

6. Casalino G., Ghorbel E. (2008), Numerical model of $\mathrm{CO}_{2}$ laser welding of thermoplastic polymers, Journal of Materials Processing Technology, 207, 63-71.

7. Ciszewski A., Radomski T. (1989), Construction materials in machine design (in Polish), PWN, Warszawa.

8. Cocard M., Grozav I., lacob M., Caneparu A. (2009), Establishing the Optimum Welding Procedure for PE 100 Polyethylene Pipelines Using the Response Surface Design, Materiale Plastice, 46(4), 452-457.

9. Domek G., Dudziak M. (2011), Energy Dissipation in Timing Belts Made From Composite Materials, Advanced Material Research, 189-193, 4414-4418. 
10. Domek G., Kołodziej A., Dudziak M., Woźniak T. (2016), Identification of the quality of timing belt pulleys, Procedia Engineering, 177, 275-280.

11. Evers F., Schöppner V., Lakemeyer P. (2017), The influence on welding processes on the weld strength of flame-retardant materials, Weld World, 61, 161-170.

12. Fierek A., Malujda I., Talaśka K. (2019), Design of a mechatronic unit for applications of coats of adhesive, MATEC Web of Conferences, 254, 01019.

13. Górecki J., Malujda I., Wilczyński D. (2019), The influence of geometrical parameters of the forming channel on the boundary value of the axial force in the agglomeration process of dry ice, MATEC Web of Conferences, 254, 05001.

14. Grewell D., Benatar A. (2007), Welding of plastics: fundamentals and new developments, International Polymer Processing, 22(1), 43-60.

15. Groover M. P. (2015), Fundamentals of modern manufacturing, Willey, 503-510.

16. Inoue T., Miyata R., Hirai S. (2016), Antagonistically Twisted Round Belt Actuator System for Robotic Joints, Journal of Robotics and Mechatronics, 28(6), 842-853.

17. Jasiulek P. (2006), Joining of plastics by welding, glueing and laminating (in Pollish), Wydawnictwo "KaBe", Krosno.

18. Klimpel A. (1999), Metals and thermoplastic polymers welding technology (in Polish), Wydawnictwo Politechniki Ślaskiej, Gliwice.

19. Klimpel A. (2000), Welding of thermoplastics materials (in Polish), Wydawnictwo Politechniki Ślaskiej, Gliwice.

20. Krawiec P., Grzelka M., Kroczak J., Domek G., Kołodziej A. (2019), A proposal of measurement methodology and assessment of manufacturing methods of nontypical cog belt pulleys, Measurement, $132,182-190$.

21. Krawiec P., Waluś K., Warguła Ł., Adamiec J. (2018), Wear evaluation of elements of $\mathrm{V}$-belt transmission with the application of the optical microscope, MATEC Web of Conferences, 157, 01009.

22. Krishnan C., Benatar A. (2004), Analysis of Residual Stress in Hot Plate Welded Polycarbonate, ANTEC 2004 Proceedings: Plastics, 1149-1153.

23. Kukla M., Tarkowski P., Górecki J., Malujda I., Talaśka K. (2015), The Effect of Magnetic Field on Magnetorheological Composites. Artificial Neural Network Based Modelling and Experiments, Applied Mechanics And Materials, 816, 327-336.

24. Madej M., Ozimina D. (2010), Plastics and composite materials (in Polish), Wydawnictwo Politechniki Świętokrzyskiej, Kielce.

25. Marciniak Z. (1959), Punching dies construction (in Polish), WNT, Warszawa, 299-302.

26. Mokhtarzadeh A., Benatar A. (2012), Experiments with conventional and high temperature hot plate welding of thermoplastics using temperature and pressure control, ANTEC 2012 Proceedings: Plastics, 1684-1690.

27. Nieh J., Lee J. (1992), Hot Plate Welding of Polypropylene Part I: Crystallization Kinetics, Polymer Engineering and Science, Vol. 38, $1121-1132$.

28. Osiński Z. (2007), Basics of machine design (in Polish), PWN, Warszawa, 157-163.

29. Pietrzak M., Wałęsa K., Górecki J., Berdychowski M. (2019) Analysis of the friction (spin) welding - preliminary study, MATEC Web of Conferences, 254, 02036.

30. Potente H., Schneiders J., Bornemann M. (2002), Theoretical model for the one-dimensional temperature and stress calculation of simple hot plate welded geometries, Macromolecular Materials and Engineering, 287, 843-853.

31. Puszka A. (2006), Polyurethanes - sources, properties and modifications (in Polish), Zakład Chemii Polimerów, Wydział Chemii Uniwersytetu Marii Curie Skłodowskiej w Lublinie, Lublin.

32. Rzasinski R. (2017), The algorithm of verification of welding process for plastic pipes, IOP Conference Series: Materials Science and Engineering, 227, 012113.

33. Sikora R. (1993), Polymers processing (in Polish), Wydawnictwo ŻAK, Warszawa.
34. Talaśka K,. Ferreira A. (2017), An Approach to Identifying Phenomena Accompanying Micro and Nanoparticles in Contact With Irregular Vessel Walls, Transactions on NanoBioscience, 16(6), 463-475.

35. Talaśka K. (2018), Study of research and modelling of the loose and shredded materials compaction process (in Polish), Wydawnictwo Politechniki Poznańskiej, Poznań.

36. Troughton M. (1997), Handbook of Plastics Joining: A practical guide, Plastics Design Library, New York.

37. Wałęsa K., Malujda I., Talaśka K. (2018), Butt welding of round drive belts, Acta Mechanica et Automatica, 12(2), 115-126.

38. Wałęsa K., Malujda M., Górecki J., Wilczyński D. (2019), The temperature distribution during heating in hot plate welding process, MATEC Web of Conferences, 254, 02033.

39. Wałęsa K., Mysiukiewicz O., Pietrzak M., Górecki J., Wilczyński D. (2019), Preliminary research of the thermomechanical properties of the round drive belts, MATEC Web of Conferences, 254, 06007.

40. Wanqing L., Changqing F., Xing Z., Youliang C., Rong Y., Donghong L. (2017), Morphology and thermal properties of polyurethane elastomer based on representative structural chain extenders, Thermochimica Acta, 653, 116-125.

41. Wilczyński D., Malujda M., Górecki J., Domek G. (2019), Experimental research on the proces of cutting transport belts, MATEC Web of Conferences, 254, 05014.

42. Wojtkowiak D., Talaśka K. (2019), Determination of the effective geometrical features of the piercing punch for polymer composite belts, The International Journal of Advanced Manufacturing Technology, https://doi.org/10.1007/s00170-019-03746-7.

43. Wojtkowiak D., Talaśka K., Malujda I., Domek G. (2018), Estimation of the perforation force for polimer composite conveyor belts taking into consideration the shape of the piercing punch, The International Journal of Advanced Manufacturing Technology, 98(9-12), 2539-2561.

44. Yousepour A., Hojjari M., Immarigeon J-P. (2004), Fusion Bonding/Welding of Thermoplastic Composites, Journal of Thermoplastic Composite Materials, 17, 303-341.

45. Żuchowska D. (2000), Construction polymers (in Polish), WNT, Warszawa. 